\title{
A Comparison of Predicted Wind Turbine Blade Loads to Test Measurements
}

\author{
A. D. Wright \\ R. W. Thresher
}

January 1987

Prepared for the

Sixth ASME Wind Energy Symposium

Dallas, Texas

16-18 February 1987

Prepared under Task No. 4829.100

FTP No. 608

Solar Energy Research Institute

A Division of Midwest Research Institute

1617 Cole Boulevard

Golden, Colorado 80401-3393

Prepared for the

U.S. Department of Energy

Contract No. DE-AC02-83CH10093 


\section{NOTICE}

This report was prepared as an account of work sponsored by the United States Government. Neither the United States nor the United States Department of Energy, nor any of their employees, nor anv of their contractors, subcontractors, or their employees, makes any warranty, expressed or implied. or assumes any legal liability or responsibility for the accuracy, completeness or usefulness of any information, apparatus, product or process disclosed, or represents that its use would not infringe privately owned rights.

\section{Printed in the United States of America Available from: \\ National Technical Information Service \\ U.S. Department of Commerce \\ 5285 Port Royal Road \\ Springiield, VA 22161}

Price: Microitiche A01

Printed Copy A02

Codes are used for pricing all publications. The code is determined by the number of pages in the publication. Information pertaining to the pricing codes can be found in the current issue of the following publications. which are generally available in most libraries: Energy Research Aostracts. (ERA): Government Reports Announcements and Index (GRA and I); Scientific and Technical Abstract Reports (STAR); and publication. NTIS-PR-360 available from NTIS at the above address. 


\title{
A COMPARISON OF PREDICTED WIND TURBINE
}

BLADE LOADS TO TEST MEASUREMENTS

\author{
A. D. Wright \\ R. W. Thresher \\ Solar Energy Research Institute \\ Wind Energy Research Center \\ Golden, CO 80401
}

\section{ABSTRACT}

The accurate prediction of wind turbine blade loads and response is important in predicting the fatigue life of wind machines. At the SERI Wind Energy Research Center, a rotor code called FLAP (Force and Loads Analysis Program) is currently being validated by comparing predicted results to machine measurements.

The FLAP code has been modified to allow the teetering degree of freedom. This paper describes these modifications and comparisons of predicted blade bending moments to test measurements. Wind tunnel data for a $1 / 20$ th scale model will be used to compare FLAP predictions for the cyclic flap-bending moments at the $33 \%$ spanwise station for three different wind speeds. The comparisons will be made for both rigid and teetering hubs.

Currently, the FLAP code accounts for deterministic excitations such as wind shear, tower shadow, gravity, and prescribed yawing motions. Conclusions will be made regarding the code's accuracy in predicting the cyclic bending moments.

\section{NOMENCLATURE}

$\begin{array}{ll}A_{0}, A_{1}, \ldots & \begin{array}{l}\text { coefficients in wind shear profile } \\ \text { distance from nacelle yaw axis to rotor } \\ \text { hub } \\ \text { rotor diameter } \\ \text { blade elastic modulus }\end{array} \\ f_{0}(r), f_{1}(r) \ldots & \begin{array}{l}\text { polynomials in wind shear expansion } \\ \text { distance from rotor spin axis to flex- } \\ \text { ible portion of the blade }\end{array} \\ I_{x_{p}, I_{p}} & \begin{array}{l}\text { area moment of inertia } \\ M_{x_{p}, M_{p}, M_{z}}\end{array} \\ M_{n c}, M_{n s} & \begin{array}{l}\text { internal bending moments about prin- } \\ \text { magnitude of harmonic content of flap- } \\ \text { wise bending moment } \\ \text { per revolution }\end{array}\end{array}$

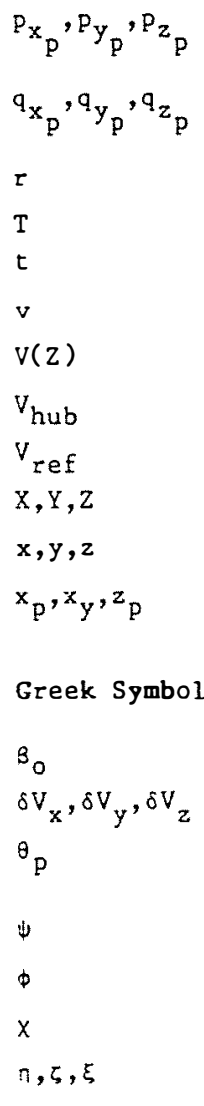

\section{INTRODUCTION}

The accurate prediction of rotor blade loads and stresses is important in order to predict the fatigue life of wind turbines. A clear need exists in the WECS community for verified codes in which the results have been compared to measured blade loads for a variety of machines and operating conditions.

\author{
force loading in the principal direc- \\ tions \\ tions \\ blade coordinate \\ blade tension force \\ time \\ blade displacement in the $y_{p}$ direction \\ wind shear profile \\ hub height mean wind speed \\ wind speed at reference height $z_{r}$ \\ fixed coordinates \\ blade coordinates \\ blade coordinates located on the blade \\ principal area inertia axes
}

blade precone angle

fluctuating components of wind velocity

angle of blade (tip) principal area inertia axes

blade azimuth angle $(\psi=0$, blade up)

nacelle yaw angle

nacelle tilt angle

final blade coordinates attached to deformed blade. 
Past comparisons of wind turbine rotor load predictions with field test data have shown rather large discrepancies. For example, Figure 1 [taken from (1)] illustrates the significant underprediction of Boeing, MOD-2 root bending moment when comparing field test measurements with computations obtained using FLAP, which was developed by the SERI Wind Energy Research Center.

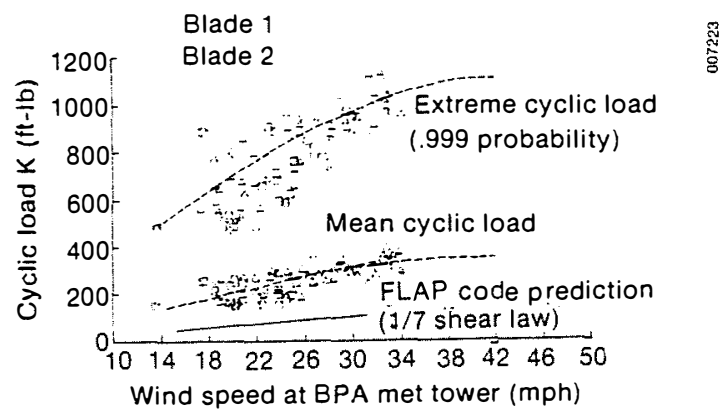

Fig. 1. Cyclic flapwise moments at Blade Station 370 (Unit $\$ 2,70 \%$ VG) from (1)

These large differences are generally attributed to the fact that the exact inflow velocity distribution is unknown. Turbulence fluctuations and even the mean wind flow field are not completely known over the rotor disk plane. This makes it difficult to directly compare field test data with analytical predictions.

For this reason, FLAP code predictions have been compared to wind tunnel test results where the inflow to the model rotor was more precisely known. In this case, the wind tunnel model was a $1 / 20$ th scale version of the MOD-2 wind turbine. The FLAP code was used to predict the dynamic behavior of the $1 / 20$ th scale model for a direct physical comparison. The focus of this study was to learn how well a simple rotor code (FLAP) could predict the rotor responses of a wind turbine, when the inflow was steady and reasonably well known. In this way, discrepancies between measured and predicted responses could be investigated with some hope of determining the source of the error, and the code could be validated for the case of a steady inflow before proceeding to more difficult situations involving unsteady flow and turbulence.

\section{FLAP CODE DESCRIPTION}

\section{General Description}

The original FLAP model allowed only flapping motion of an individual wind turbine blade $(2,3)$. Recently, the FLAP code was modified to analyze teetering rotors as well. For the teetering rotor analysis, two asymmetric (rigid body teeter and asymmetric flap-bending) and two symmetric modes are included. The rotor is assumed to rotate at a constant rotor speed and the hub can be allowed to move in a prescribed yawing motion. At this time, neither tower motion nor control system actions are accounted for in the FLAP code analysis, but these can be added in the future if the need arises. Rotors that are tilted and yawed relative to the mean flow can also be analyzed.

The model includes the effects of wind shear and tower shadow. As will be shown later, accurate modeling of a highly nonlinear wind shear profile is important for prediction of blade loads for rotors which are upwind of the tower. The FLAP code can be easily modified to input nonlinear wind shear profiles using polynomial distributions of different orders, rather than just a simple power law shear profile.

\section{Coordinate System Definitions}

Figure 2 shows the orientation of the turbine blade under analysis with all the intermediate coordinates required to represent the blade motion. The capital X, $Y, Z$ coordinates are the fixed reference system. The mean wind velocity at the hub, $V_{\text {hub }}$, and its fluctuating components, $\delta V_{X}, \delta V_{Y}$, and $\delta V_{Y}$, are given in this system. The rotor spin axis is allowed to tilt through a fixed angle $x$, and the rotor is allowed to have a prescribed time-dependent yawing motion given as $\phi(t)$, where $\phi$ is the yaw angle. The yaw axis is coincident with the. $z$ coordinate axis. The hub, located at distance "a" from the yaw axis, is considered to be rigid and to have some radius, h. The flexible portion of the blade begins at the outer hub radius, $h$. The airfoil shape may begin at $h$ or at some position further out along the blade $z$ axis. The blade is coned at some angle $B$, as shown in the figure.

The $x, y$, and $z$ coordinates are located in the surface of revolution that a rigid blade would trace in space, with the $y$ axis normal to this surface. The $x_{p}, y_{p}$, and $z_{p}$ axes are the blade principal bending coordinates, where the $z_{p}$ axis is coincident with the elastic axis of the underformed blade. Bending takes place about the $x_{p}$ coordinate. It is further assumed that the blade principal axes of area inertia do not change along the $z_{p}$ axis. The influence of blade twist on bending displacement is neglected. The orientation

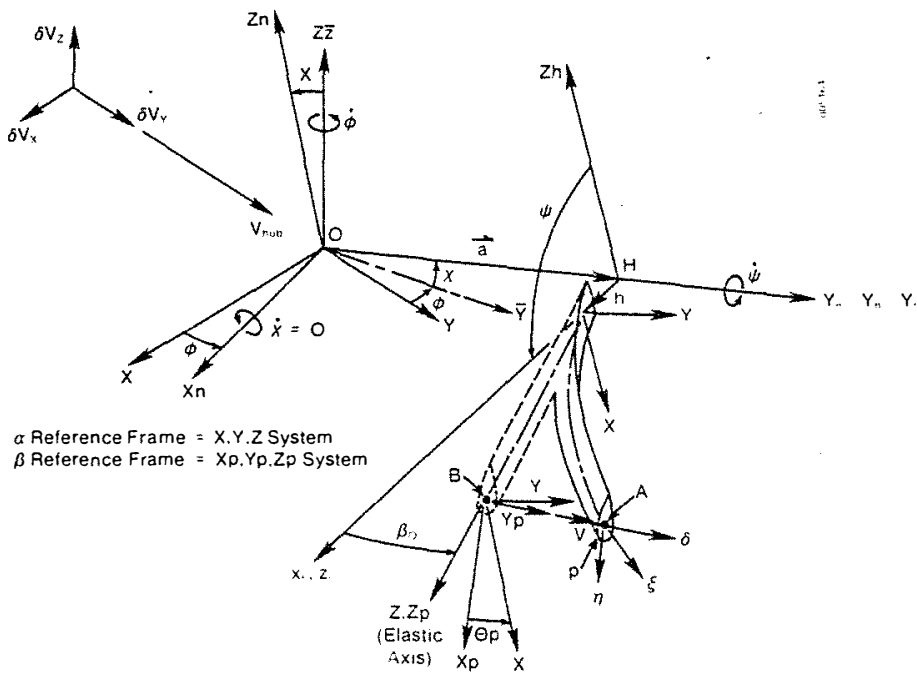

Fig. 2. Illustration of the rotor system coordinates with positive displacements and rotations shown

used to set the angle $\theta_{p}$ for computations is the principal axis near the blade tip, because the deformation is largest there. The final coordinate system is the $\eta, \zeta, \xi$ system, which is on the principal axes of the ceicormed blade at some point along the elastic axis.

\section{Equilibrium Equations}

The blade is assumed to be a long slender beam so that normal strength of materials assumptions concerning the bending deformation are valid. Then equilibrium equations for a simple beam loaded by applied 
forces per unit length, $p_{x_{p}}, p_{y_{p}}$, and $p_{z_{p}}$ and moments per unit length, $q_{x_{p}}, q_{y_{p}}$, and $q_{z_{p}}$ can be written in the form

$$
\begin{array}{ll}
\text { Flap: } & \left(-v^{\prime \prime} E I_{y_{p}}\right)^{\prime \prime}+\left(T v^{\prime}\right)^{\prime}+q_{x_{p}}^{\prime}+p_{y_{p}}=0 \\
\text { Lead-Lag: } & M_{y_{p}}^{\prime \prime}+q_{y_{p}}^{\prime}-p_{x_{p}}=0 \\
\text { Torsion: } & M_{z_{p}}^{\prime}+M_{y_{p}}^{\prime} v^{\prime}+q_{y_{p}} v^{\prime}+q_{z_{p}}=0 \\
\text { Tension: } & T^{\prime}+p_{z_{p}}=0,
\end{array}
$$

where primes (','') indicate partial differentiation with respect to $z_{p}$ and $v$ is the flapping displacement; $M_{x_{p}}$, $M_{y_{p}}$, and $M_{z p}$ are the internal bending moments; and $T$ is the blade axial tension. The only equilibrium relationship which results in an equation of motion is for the flap-direction, since only flapping displacements have beèn allowed. The other equations simply provide static relationships, which must be solved for the internal forces and moments.

\section{Aerodynamic Forces}

The code is configured to use a quasi-steady linear aerodynamic model to compute the blade aerodynamic forces. However, the lift curve slope can be varied as a function of position along the rotor span so that the lift coefficients do not become unreasonably large near the hub, where the flow is usually stalled. The code computes the aerodynamic forces at each time step for all radial blade stations, so that more sophisticated time dependent aerodynamic models could be used if needed. As will be shown, this particular study provides little motivation for more sophisticated models.

\section{Computer Solution}

The FLAP code operates in the time domain, and the blade acceleration equation is integrated via a modified Euler trapezoidal predictor-corrector method. The method involves the use of a set of low order relations, is self-starting and stable, and allows frequent step size changes. The procedure is entirely automated within the computer program. Results of the blade loads analysis are printed in tabular form and include the deflection, slope, velocity, flapwise shear and moment, edgewise shear and moment, blade tension, and blade twisting moment for any point along the blade axis.

The program, written in FORTRAN 77 , is in the public domain and was developed for easy end-user modification and customization. A substantial effort has been made to make the actual code contain its own documentation through extensive use of comments within the program. The reader wishing further details on the FLAP code and its formulation is referred to (2) and (3).

\section{WIND TUNNEL TEST}

The wind tunnel testing of the $1 / 20$ th scale model of the MOD-2 wind turbine was performed in the Boeing Vertol low speed wind tunnel during May of 1978. The testing was done in support of the development of the MOD-2 wind turbine system to verify the deterministic design loads predicted by the dynamic analysis codes MOSTAB and MOSTAS. This testing and comparison effort is reported in ( $\underline{4}$ ).

\section{The Test Model}

The test model was a $1 / 20$ th scale dynamic model with a $15 \mathrm{ft}$ diameter rotor mounted on a $10 \mathrm{ft}$ tower. The rotor had $8^{\circ}$ twist, which varied linearly from the tip to the $20 \%$ spanwise location. The chord was also linearly tapered from $0.235 \mathrm{ft}$ at the tip to $0.613 \mathrm{ft}$ at the $20 \%$ span location. The airfoil used was a NACA 23024. Table 1 summarizes the blade weight distribution. twist, chord, flapwise bending stiffness, edgewise bending stiffness, and airfoil section as a function of spanwise location.

The weight distribution is also plotted as a function of blade spanwise station in Figure 3, while the stiffness distributions are plotted in Figure 4. The NACA 23024 lift curve for a Reynolds number of $6.5 \times$ $10^{5}$ is reproduced in Figure 5. This curve was used to characterize the aerodynamic properties of the rotor for this study.

The rotor hub could be locked to operate in a cantilevered blade attachment mode, or unlocked to operate in a teetering mode. For the teetering mode,

Table 1. Blade Properties for the $1 / 20$ th Scale Wind Tunnel Model

\begin{tabular}{lccccccccccc}
\hline blade span (ft) & 0.00 & 0.25 & 0.251 & 1.25 & 1.251 & 1.50 & 1.51 & 2.70 & 5.10 & 5.42 & 7.50 \\
\hline $\begin{array}{l}\text { distributed weight } \\
\text { (lb/ft) }\end{array}$ & 1.80 & 1.80 & 5.74 & 5.74 & 1.45 & 1.15 & 1.42 & 1.10 & 0.49 & 0.43 & 0.21 \\
\hline $\begin{array}{l}\text { flapwise stiffness } \\
\left(\times 10^{6} \text { lb-in. }\right)\end{array}$ & 15.17 & 15.17 & 10.96 & 10.96 & 9.98 & 8.01 & 8.00 & 3.52 & 1.20 & 0.85 & 0.09 \\
\hline $\begin{array}{l}\text { edgewise stiffness } \\
\left(\times 10^{6} \text { lb-in. }\right)\end{array}$ & 23.00 & 23.00 & 17.40 & 17.40 & 17.06 & 13.85 & 18.78 & 9.09 & 5.40 & 2.68 & 0.50 \\
\hline $\begin{array}{l}\text { twist (degree, for } \\
\text { zero pitch setting) }\end{array}$ & 0.00 & 0.00 & 0.00 & 0.00 & 0.00 & 0.00 & 5.51 & 4.00 & 0.70 & 0.30 & -2.50 \\
\hline chord (ft) & 0.225 & 0.225 & 0.225 & 0.225 & 0.225 & 0.225 & 0.613 & 0.538 & 0.385 & 0.365 & 0.235 \\
\hline airfoil section (NACA) N/A & N/A & N/A & N/A & N/A & N/A & 23028 & 23027 & 23022 & -- & 23012 \\
\hline
\end{tabular}

Other Input Parameters: Precone $=0^{\circ}$, Hub height $=10 \mathrm{ft}$, Rotor Speed $=350 \mathrm{rpm}$, Shaft tilt $=0^{\circ}$.

Collective pitch settings: $0^{\circ}$ for $20 \mathrm{mph}, 9.29^{\circ}$ for $30 \mathrm{mph}$, $19.97^{\circ}$ for $45 \mathrm{mph}$. 


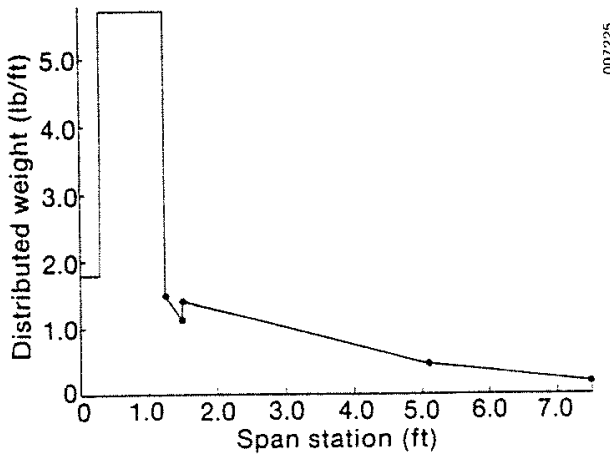

Fig. 3. 1/20th scale model blade distributed weight

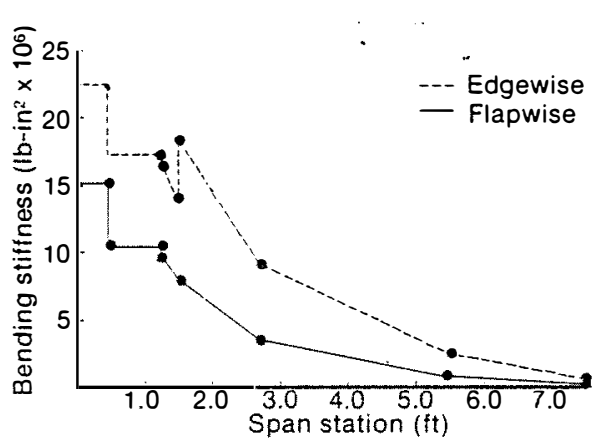

Fig. 4. 1/20th scale wodel blade flapwise and edgewise stiffness distributions

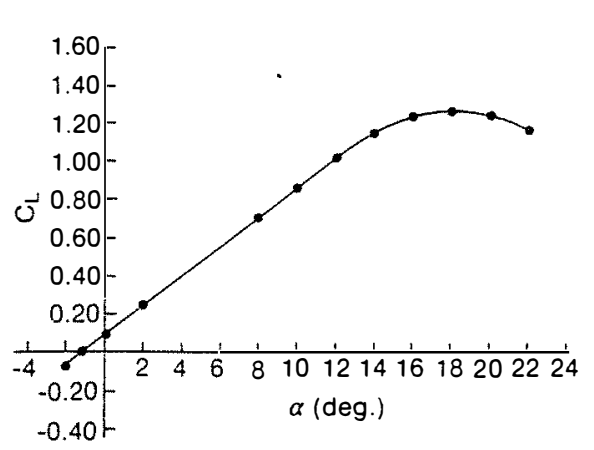

Fig. 5. Lift curve for the NACA 23024 airfoil at Reynolds number $=6.5 \times 10^{5}$

the hub had $45^{\circ}$ of delta-3, which could not be varied. The collective pitch of the rotor could be manually adjusted to any desired seting. In this model, the entire span of the blade was rotated when the collective pitch was varied. For the prototype MOD-2s, tip control of the outer $30 \%$ of the span was used.

The power absorption and drive train characteristics of the MOD-2 prototype were not modeled. Rotor torque was absorbed by a hydraulic pump through a 6 to 1 speed increaser, and the power dissipation was controlled with a flow restriction value. During testing, the absorber malfunctioned and only about $1 / 3$ of the desired power could be absorbed. Therefore, the model could not be operated at higher power levels, which restricted the testing envelope.
The model was Mach scaled, and an effort was made to simulate the scaled frequency, mass, and stiffness characteristics of the prototype MOD-2. The measured model characteristics are tabulated in Table 2.

Table 2. Wind Tunnel Model Characteristics [taken from (ㄴ) ]

\begin{tabular}{lc}
\hline \multicolumn{1}{c}{ Model Parameters* } & Measured Results \\
\hline Blade flapwise frequency & $2.76 \mathrm{P}$ \\
Blade chordwise frequency & $7.13 \mathrm{P}$ \\
System bending frequency & $1.10 \mathrm{P}$ \\
Rotor weight & $32.4 \mathrm{lb}$ \\
Nacelle weight & $89.65 \mathrm{~b}$ \\
Tower weight & $75.0 \mathrm{lb}$ \\
Rotor diameter & $15.0 \mathrm{ft}$ \\
Tower Height & $10.0 \mathrm{ft}$ \\
\hline
\end{tabular}

$\approx$ Rotor speed $\approx 350 \mathrm{rpm}$

The $1 / 20$ th scale model frequency, stiffness, and mass characteristics are somewhat different than those for the prototype MOD-2 turbines finally fabricated. That is not a problem for this work. The intent of this study is to compare the measured response of a physical turbine to the predicted response operating in a well defined wind environment.

The Tunnel Environment

The $15 \mathrm{ft}$ diameter scale model was installed in the test section of the Boeing Vertol $20 \mathrm{ft} \times 20 \mathrm{ft}$ low speed wind tunnel. Wire mesh screens were installed in the tunnel to develop a wind shear profile that resembled the theoretical gradients. Various mesh configurations were installed and evaluated in an effort to match the theoretical wind velocity profile, $V(z)$, given by

$$
v(z)=v_{\text {ref }}\left(z_{r}\right) \frac{\ln \left(z / z_{o}\right)}{\ln \left(z_{r} / z_{o}\right)},
$$

where $Z$ is the height above the tunnel floor with $z_{r}=1.5 \mathrm{ft}$ and $z_{0}=0.008$. The wind gradient actually provided by the screens was measured at tunnel wind speeds of 20,30 , and $45 \mathrm{mph}$ at a location $4.67 \mathrm{ft}$ $(0.31 \mathrm{D})$ upwind of the rotor plane. The measured wind gradient profiles are compared with the theoretical gradient in Figure 6. The measured distribution is on the average a pretty good approximation to the theoretical profile, but is quite nonlinear. These largest nonlinearities occur in regions where the mesh screens overlapped. It was initially felt that the nonlinearities where unimportant for loads prediction because

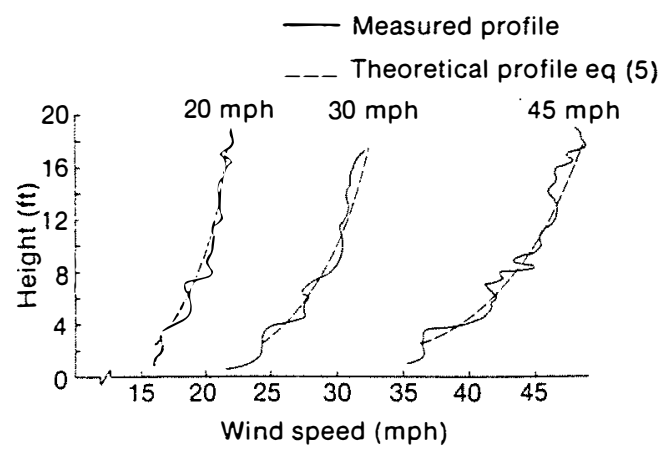

Fig. 6. Comparison of measured and theoretical wind shear profiles, from (4) 
they would appear as high frequency wind fluctuations as the rotor swept through at high speed, and there would be little blade dynamic response. However, that assumption will be shown to be wrong.

No wind tunnel blockage factors were applied to the raw data. The tunnel test section had slotted walls, which were intended to eliminate the need for blockage corrections. Figure 7 shows the model turbine installed in the tunnel, and it illustrates the slotted walls along the test section. As a further verification that blockage was not a significant issue for this study, the mean flap bending moments as predicted by the FLAP code were found to agree with the measured mean loads to within about 10-15\%.

Wind velocities and gradients were measured using pitot tubes, and only mean velocities were reported. For this reason, it is impossible to determine the turbulence level in the tunnel during testing. It has been assumed for this study that the tunnel turbulence

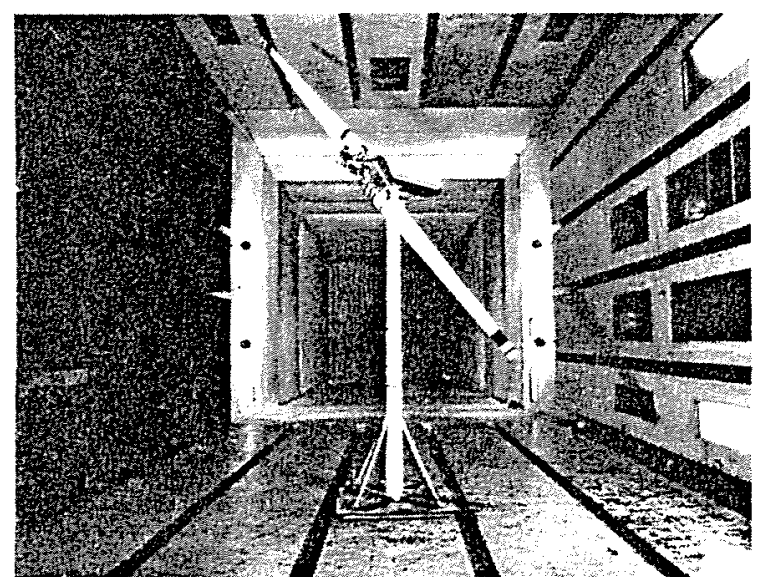

Fig. 7. 1/20th scale model in tunnel

level was much smaller than for atmospheric test conditions, and that the cyclic loads were not significantly influenced by turbulence. One particular test run (Run 13) was recorded for 20 revolutions, and the mean bending moment for each revolution varied from the average for all revolutions by less than $2 \%$, while the maximum cyclic load varied from the average cyclic by less than $14 \%$. This is much better than during atmospheric tests, where the cyclic loads often vary by a factor of 2 to 5 , as is illustrated in Figure 1.

\section{Test Conditions}

The wind tunnel test generated an extensive data base, and only a limited quantity has been reviewed and used for this study. The data for tests were run at 20,30 , and $45 \mathrm{mph}$ and yaw angles of $0^{\circ}, 20^{\circ}$, and $-20^{\circ}$ with the locked (rigid) hub and unlocked (teetered) hub. These measurements are then compared to FLAP code predictions.

Strain gages were attached to the $1 / 20$ th scale model at the $33 \%$ blade spanwise station to measure bending loads in the flapwise and edgewise directions. For this study, only flapwise bending moments are compared with the FLAP code predictions. For comparison, the experimental measurements are expressed as harmonics of rotor blade angular position in the general form $\begin{aligned} M(\psi)=M_{0} & +M_{1 c} \cos \psi+M_{1 s} \sin \psi \\ & +M_{2 c} \cos 2 \psi+M_{2 s} \sin 2 \psi \\ & +M_{3 c} \cos 3 \psi+M_{3 s} \sin 3 \psi+\ldots,\end{aligned}$

where $M$ is the flapwise bending moment, $\psi$ is the blade angular position with $\psi=0$ taken for the straight-up position. The coefficients $M_{n c}$ and $M_{n s}$ define the magnitude of the harmonic content of the flapwise bending response. For the comparison made in this paper, the magnitude of the nth harmonic is defined as

$$
\left|M_{n}\right|=\left\{M_{n c}^{2}+M_{n s}^{2}\right\}^{\frac{1}{2}} \text {. }
$$

The steady load is given by $M_{0}$, and the cyclic load is the remainder of the series given by

$$
\text { Mcyclic }=\sum_{n=1}^{m}\left(M_{n c} \cos n \psi+M_{n s} \operatorname{sinn} \psi\right) \text {. }
$$

\section{COMPARISON OF PREDICTED AND MEASURED RESPONSE}

The rigid hub data set for $30 \mathrm{mph}$ and zero yaw angle was selected for initial comparison studies. The FLAP code was run using a simple $1 / 7$ power law wind shear profile. It was quickly found that this did an excellent job of predicting the first harmonic (IP) bending moment, but underpredicted the second harmonic (2P) by about $40 \%$. These results were virtually identical to those obtained in 1978 by Shipley (4) when attempting to validate the MOSTAB code using this same data.

In an effort to improve the prediction for the second harmonic of the bending response, eventually a better approximation was made for the wind shear profiles shown in Figure 6 . For the $30 \mathrm{mph}$ case, first a cubic least square fit to the profile was obtained and then transformed into a harmonic expansion in terms of the rotor coordinates, $r$ and $\psi$. For the case of a cubic polynomial wind profile this has the specific form

$$
V(Z)=A_{0}+A_{1} Z+A_{2} Z^{2}+A_{3} Z^{3}
$$

where $Z$ is vertical height, with the zero reference taken as hub height. Substituting $z=r \cos \psi$ transforms this equation into rotor blade coordinates resulting in the expression

$$
\begin{aligned}
V(z)= & \left(A_{0}+1 / 2 A_{2} r^{2}\right)+\left(A_{1} r+3 / 4 A_{3} r^{3}\right) \cos \psi \\
& +\left(1 / 2 A_{2} r^{2}\right) \cos 2 \psi+\left(1 / 4 A_{3} r^{3}\right) \cos 3 \psi .
\end{aligned}
$$

This expression, when introduced as the rotor excitation, gave a better prediction for the response of the second harmonic. Following this success, ninth order polynomials and in some cases even 20th order polynomials where used to obtain wind shear excitations that included the influence of the nonlinearities in the profile. The wind profile equations where written in the form

$$
\begin{aligned}
V(z)= & f_{0}(r)+f_{1}(r) \cos \psi+f_{2}(r) \cos 2 \psi+f_{3}(r) \cos 3 \psi \\
& +f_{4}(r) \cos 4 \psi+f_{5}(r) \cos 5 \psi,
\end{aligned}
$$

where the $f$ values are polynomials in $r$ beginning with $r^{n}$, similar to the previous expression developed for the cubic wind profile. The harmonic expansion was truncated at the fifth harmonic because the test data was reported only up to five harmonics. In addition, the experimental measurements showed that only the first two harmonics were important. 


\section{Rigid Hub Comparigons}

The wind shear profile was approximated with both a cubic and a ninth order polynomial for the $30 \mathrm{mph}$ case. Figure 8 shows a comparison of the FLAP code predictions using both the cubic profile and the ninth order approximation. The ninth order wind profile clearly provides a better prediction of response, but it is not perfect. Figure 9 shows the harmonic content of these results and clearly illustrates the improvement from the addition of the nonlinearities to the wind profile.

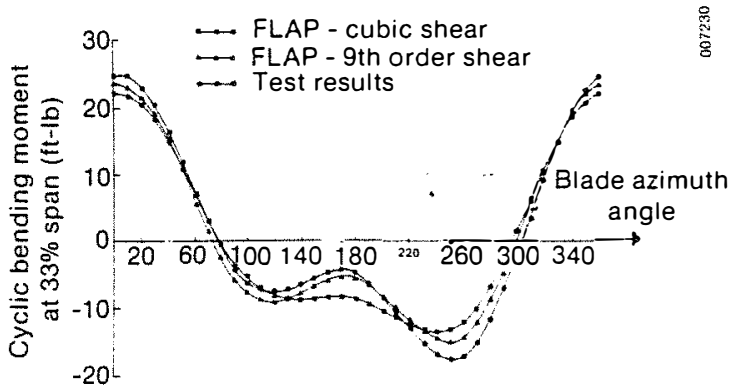

Fig. 8. Comparison of FLAP code predictions with wind tunnel measurements for the rigid hub configurations at $30 \mathrm{mph}$

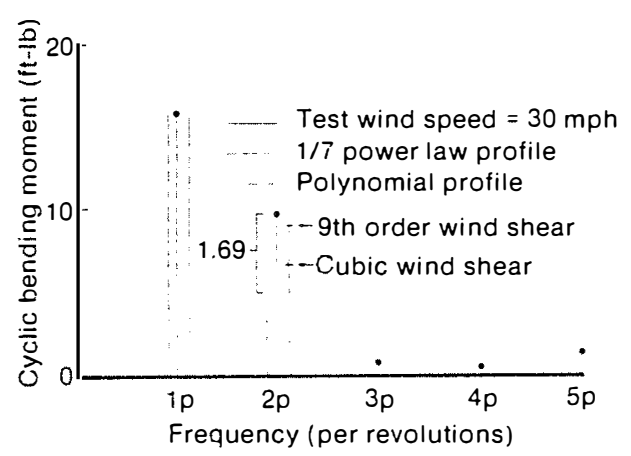

Fig. 9. Harmonic content of flapwise moment for the rigid hub configuration at $30 \mathrm{mph}$

The harmonic content for both the $20 \mathrm{mph}$ case and the $45 \mathrm{mph}$ case are shown in Figure 10. Notice that even using a 20 th order approximation for the $45 \mathrm{mph}$ wind speed profile does not reduce the error as much as it did for the lower wind speed cases. The exact cause of this residual error is unknown, but a comparison of the 20 th order polynomial wind profile with the actual measured profile does indicate a poor fit near hub height, as shown in Figure 11. Because this discrepancy is near hub height and extends entirely across the wind tunnel, it will tend to act like an impulsive loading applied to the entire rotor as the blade sweeps through the horizontal position. This excitation would be expected to produce a rotor response similar to tower shadow loading for a down-wind turbine. It should be noted that this sort of condition can occur during atmospheric operation of wind turbines, even for very stable conditions, when the turbulence level is quite low.

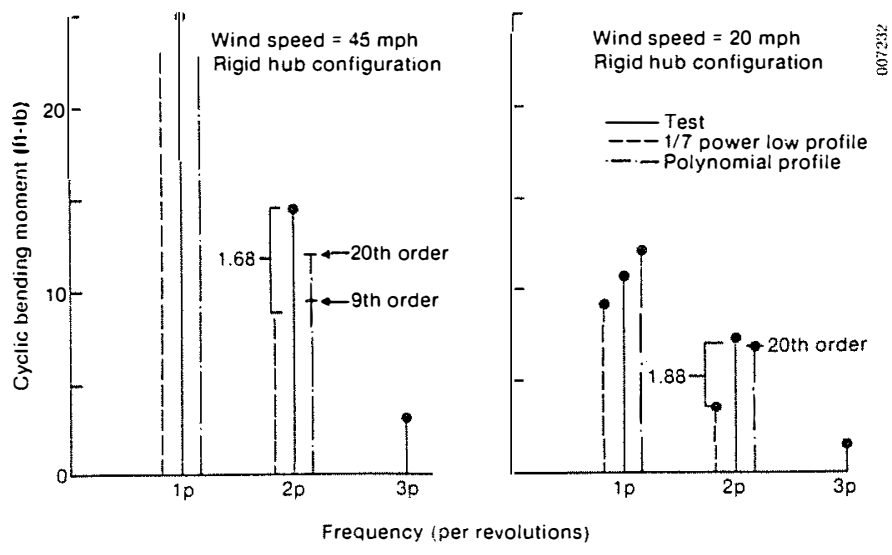

Fig. 10. Harmonic content of the flapwise moment for the rigid hub configuration at 20 and $45 \mathrm{mph}$

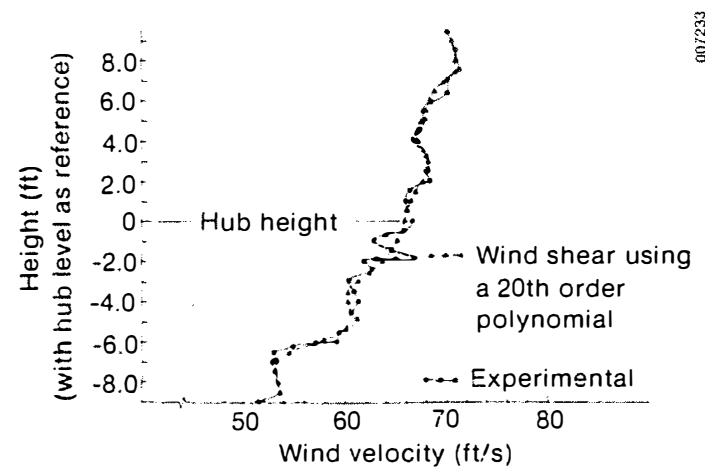

Fig. 11. Comparison of measured wind shear profile with polynomial expansion at $45 \mathrm{mph}$

Teetering Hub Comparisons

The blade flapwise bending moment waveform predictions for the $30 \mathrm{mph}$ test condition are compared in Figure 12, where the ninth order polynomial was used to approximate the wind shear profile. The waveform exhibits the expected 2 per revolution response with close agreement between the predictions and the mea-

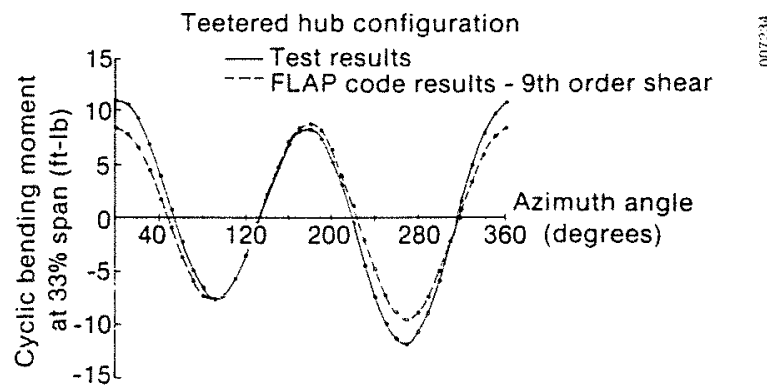

Fig. 12. Comparison of FLAP code predictions with wind tunnel measurements for the teetering hub configuration at $30 \mathrm{mph}$ 
surements. The harmonic content for 20,30 , and $45 \mathrm{mph}$ are compared in Figure 13 for the first two harmonics. As can be seen, the results indicate good agreement between the predictions and measurements with the largest discrepancy for the $45 \mathrm{mph}$ wind speed (as was the case for the rigid hub comparison). Finally, it should be remembered that the experimental model had a hub with $45^{\circ}$ of delta-3, while the FLAP code had zero delta-3. For the reader interested in looking more closely at the harmonic content of the experimental measurements, Table 3 provides the coefficients $M_{n c}$ and $M_{n s}$ through the third harmonic for both the teetering and rigid hub cases.

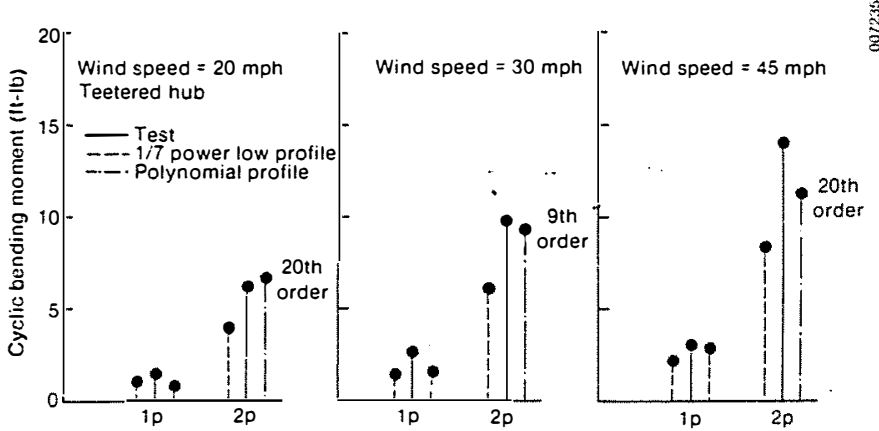

Fig. 13. Harmonic content of the flapwise moment for the teetering hub configuration at 20,30 , and $45 \mathrm{mph}$

Table 3. Wind Tunnel Blade Test Measurements for the Flapwise Bending Moments on the $1 / 20$ th Scale Model at $33 \%$ R [taken from (4 $)$ ]

\begin{tabular}{lccccccc}
\hline $\begin{array}{l}\text { Wind } \\
\text { Speed }\end{array}$ & $M_{0}$ & $M_{1 c}$ & $M_{1 s}$ & $M_{2 c}$ & $M_{2 s}$ & $M_{3 c}$ & $M_{3 s}$ \\
\hline Rigid Hub: & & & & & & \\
$20 \mathrm{mph}-103.9$ & 9.94 & 4.17 & 6.59 & -.07 & 0.43 & 0.20 \\
$30 \mathrm{mph}-38.4$ & 14.8 & 5.25 & 9.58 & -0.80 & 0.29 & 0.90 \\
$45 \mathrm{mph} \quad 1.84$ & 23.8 & 7.41 & 14.3 & -0.76 & 2.16 & 1.14 \\
Teetering & & & & & & \\
Hub: & & & & & & & \\
$20 \mathrm{mph}-92.6$ & 1.43 & 0.71 & 6.30 & 1.00 & -0.14 & -0.17 \\
$30 \mathrm{mph}-102.6$ & 1.34 & 2.12 & 9.58 & -0.33 & 0.83 & -1.02 \\
$45 \mathrm{mph}-0.65$ & 1.41 & 2.38 & 14.2 & 1.52 & 1.32 & -0.34
\end{tabular}

\section{Yawed Rotor Comparisons}

The measured and predicted bending moment harmonic content is compared in Table 4 for the rigid hub configuration with $\pm 20^{\circ}$ yaw angles at 20,30 , and $45 \mathrm{mph}$.

The cos $\psi$ term is the dominate term and increases with positive yaw angles and decreases with negative angles. In effect, it adds to the influence of the wind shear gradient or subtracts from it. The next most important term is the $\cos 2 \psi$, which appears to be relatively insensitive to yaw angle. The $\cos 2 \psi$ is responding mostly to the nonlinearities in the wind shear and ringing the blade at its natural frequency, which wouldn't be expected to change dramatically for small yaw angle variations. The sin $\psi$ and $\sin 2 \downarrow$ terms are generally smaller. The comparison between predicted and measured results is generally good with the exception of the sin $\psi$ term for $20 \mathrm{mph}$. The authors can offer no good explanation for this discrepancy.
Table 4. Comparison of FLAP Load Predictions to Scale Model Test Measurements; Flapwise Bending Moments at $33 \% \mathrm{R}$ for $\pm 20^{\circ}$ Yaw Angles at Three Different Wind Speeds (Rigid Hub Configuration).

Harmonic Content

\begin{tabular}{llllll}
\hline & $20 \mathrm{mph}$ & & $30 \mathrm{mph}$ & & $45 \mathrm{mph}$ \\
\cline { 5 - 6 } & FLAP & Test & FLAP & Test & FLAP
\end{tabular}

\begin{tabular}{lrrrrrr}
\hline$+20^{\circ}$ yaw: & & & & & & \\
$\cos \psi$ & 11.4 & 17.0 & 22.5 & 20.3 & 51.2 & 50.0 \\
$\sin \psi$ & 9.6 & 2.0 & 4.7 & 3.8 & 8.3 & 7.8 \\
$\cos 2 \psi$ & 6.7 & 5.2 & 8.5 & 10.6 & 10.4 & 15.4 \\
$\sin 2 \psi$ & -2.2 & 1.1 & 0.97 & 3.4 & -2.1 & 5.5 \\
$-20^{\circ}$ yaw: & & & & & & \\
$\cos \psi$ & 8.8 & 7.6 & 5.9 & 9.8 & -7.2 & -5.8 \\
$\sin \psi$ & -2.0 & 1.2 & 5.3 & 2.8 & 1.4 & 2.6 \\
$\cos 2 \psi$ & 7.0 & 6.0 & 9.4 & 8.9 & 9.1 & 12.1 \\
$\sin 2 \psi$ & 1.1 & 1.6 & -1.1 & 2.7 & 0.24 & 4.1 \\
\hline
\end{tabular}

\section{Closing Comments on the Comparisons}

Early in the process of making these comparisons, it became quite clear that the natural frequencies used in the FLAP code had to agree with the test model. To accomplish this, the structural properties given in Figures 3 and 4 were used as a starting approximation. The resulting blade stiffness coefficients where then adjusted to obtain a good match with the first flapping frequency of the model $(2.76 \mathrm{p})$. For the rigid hub rotor, the FLAP code was run with only this single degree-of-freedom, and for the teetered rotor, the rigid body teeter mode was added.

In the test reports of (4), it was noted that the tower motions were sometimes significant. No effort has been made to assess the importance of the tower motion, primarily because the authors felt that the comparisons were good enough without looking further.

No cases of deep stall were found for comparison. In all situations run in the wind tunnel, the pitch angle was set so that the power absorber would not be overloaded. For example, for the $45 \mathrm{mph}$ wind speed the pitch angle was set $20^{\circ}$ toward center. Even though the inboard blade stations are stalled, the attached flow at the outboard stations still dominates the loads generated. For this reason, this comparison provides no information about stalled rotor behavior or loads.

It must be emphasized that the actual model had a delta-3 angle of $45^{\circ}$, which could not be accounted for in FLAP. The FLAP code only models simple teetering rotors with zero delta-3. For this model, the FLAP code did a reasonable job of predictirg the cyclic bending loads, even without accounting for the delta-3 angle. The reader must be cautioned that correct modeling of the delta-3 angle may be important for other rotors.

\section{CONCLUSIONS}

The FLAP code predictions for a 1/20th scale model of the MOD-2 wind turbine have been compared to wind tunnel test results for both a rigid and a teetering hub configuration, and for yawed flow operation. FLAP is a relatively sinple rotor code. It models only rotor dynamics, and for the comparison made here only a single blade bending mode was included. In addition, 
the rigid body mode was added for the teetering comparisons. The aerodynamic forces are computed using quasi-steady linear aerodynamics. The lift curve slope is entered as a function of position along the blade, which is generally adjusted downward near the hub to account for stall. In spite of these limitations, the FLAP code provided good estimates for rotor blade bending moments over the range of wind speeds from $20 \mathrm{mph}$ to $45 \mathrm{mph}$ for yaw angles up to $\pm 20^{\circ}$ for both rigid and teetered hubs. The authors feel that the following conclusions can be drawn from this study:

1. With an accurate definition of the rotor inflow, even relatively simple rotor models (like FLAP) can predict the loads accurately for situations where the angles-of-attack are small. From this study, nothing can be concluded about large angles-of-attack, where stall and dynamic stali may be important.

2. Even small velocity perturbations in the inflow have the potential to significantly influence the rotor loads. This tends to underscore the importance of developing models that can handle turbulence in the rotor inflow.

The authors would also like to advise designers to run parametric studies for new turbine concepts to explore their sensitivity to natural frequency placement. In addition, it would be wise to examine the sensitivity of the loads predictions to inflows that are rich in harmonic content, until turbulence related design models are established.

\section{ACKNOHLEDGEMENTS}

The authors would like to thank Dr. Alfred Eggers of RANN Inc. for suggesting that we take a look at this wind tunnel data because it was the one data set in existence with known inflow and low turbulence. In addition, without the help of Stan Shipley at Boeing in recovering the data, the study would have been impossible. Finally, both Stan Shipley and Gary Miller assisted with the interpretation of the data and reports.

\section{REFERENCES}

1. Bovarnick, M. L., Shipley, S. A., and Finger, R. W., "Goodnoe Hills MOD-2 Cluster Test Program," AP4060, Vol. 2, Electric Power Research Institute, Palo Alto, Calif., May 1985.

2. Thresher, R. W. and Hershberg, E. L., "Computer Analysis of Wind Turbine Blade Static and Dynamic Loads," SERI/STR-217-2629, RFP-7684, prepared by Oregon State University for Rockwell International, Wind Systems Program, Mar. 1984.

3. Thresher, R. W., Wright, A. D., and Hershberg, E. L., "A Computer Analysis of Wind Turbine Blade Dynamic Loads," Journal of Solar Energy Engineering, Vol. 108, Feb. 1986, pp. 17-25.

4. Shipley, S. A., "Wind Tunnel Test, WTS MOD-2, Full Span Control, 1/20th Scale," nonpublished report on wind tunnel experiment, Code IDENT. No. 81205 D27710129-1, Boeing Aerospace Company, Seattle, Wash. 